\title{
Intelligent Data-Driven Models for Simulating Formwork Labour Productivity in High Rise Buildings
}

\author{
Nehal Elshaboury1, Abobakr Al-Sakkaf',3, Ghasan Alfalah4 \\ Eslam Mohammed Abdelkader 5 \\ ${ }^{1}$ Construction and Project Management Research Institute/Housing and Building National Research Centre, Giza, \\ Egypt; nehal_ahmed_2014@hotmail.com \\ 2Department of Architecture \& Environmental Planning/College of Engineering \& Petroleum/Hadhramout \\ University, Mukalla, Yemen \\ 32Department of Building, Civil and Environmental Engineering/Concordia University, Montréal, Canada; \\ abobakr.alsakkaf@concordia.ca \\ ${ }^{4}$ Department of Architecture and Building Sciences/King Saud University, Riyadh, Saudi Arabia; \\ galfalah@ksu.edu.sa \\ ${ }^{5}$ Structural Engineering Department/Faculty of Engineering/Cairo University, Giza, Egypt; \\ eslam_ahmed1990@hotmail.com
}

\begin{abstract}
Forecasting accurate labour productivity is critical in construction project management because construction projects are labour-intensive. This study proposes eight intelligent data-driven models for emulating formwork labour productivity in high rise buildings. These models encompass an adaptive neuro-fuzzy inference system trained using genetic algorithm (ANFIS-GA), an adaptive neuro-fuzzy inference system trained using particle swarm optimization algorithm (ANFIS-PSO), generalized regression neural network (GRNN), back-propagation artificial neural network (BP-ANN), Elman neural network (ENN), regression trees (RT), support vector machines (SVM) and Gaussian process regression (GPR). The models are applied to two high-rise buildings in Montreal, Canada to test their prediction capabilities. The accuracies of the developed data-driven models are investigated using the performance metrics of mean absolute percentage error (MAPE), mean absolute error (MAE), root-mean squared error (RMSE), root relative squared error (RRSE) and relative absolute error (RAE). The assessment metrics show that the GRNN model exhibits better and stable performance than the remainder of the prediction models (MAPE 8.98\%, MAE 0.13, RMSE 0.19, RAE 0.45 and RRSE 0.54). It is also derived that the work method and temperature sustain the high influence on labor productivity. It can be anticipated that the developed GRNN model, can be a valuable decision-making tool for forecasting construction labour productivity in construction projects.
\end{abstract}

Date Received: 2021-12-15

Date Accepted: 2021-12-22

Date Published: 2022-01-06
Keywords: Labour productivity, data-driven, high rise buildings, generalized regression neural network, regression tree, Gaussian process regression.

(C) Copyright 2022 Authors - This is an Open Access article published under the Creative Commons Attribution License terms (http://creativecommons.org/licenses/by/3.0). Unrestricted use, distribution, and reproduction in any medium are permitted, provided the original work is properly cited.

\section{Introduction}

The performance of the construction sector is critical in both developed and developing countries. This sector contributes to the gross domestic product and economic development of any country [1-3]. As a result, increasing construction productivity attracts more investment, boosts industry competitiveness, and creates job opportunities [4]. The construction sector is labour-intensive, with labour expenses accounting for $30-60 \%$ of the overall project expenditures [5-6]. Therefore, boosting labour productivity might improve the performance of building projects. However, the construction industry is confronted with several problems, including diminishing productivity growth [7].

Productivity is not used to estimate the cost of resources; rather, it quantifies the relationship between 
the resources utilized and the product produced [8-10]. In the construction industry, productivity is usually described as the ratio of an amount of output (e.g., money, product, or service) to a unit of resource input (e.g., labour, machines, materials, and money) [11]. Productivity may be quantified at three levels: industry/sector, project, and activity/process. The project productivity level is preferred since it assists construction businesses in identifying areas for improvement [12].

Quantifying and identifying the interdependencies among significant elements is required for modelling construction labour productivity. The current method of predicting productivity rates is based on an estimator's opinion, published productivity data, or previous project data. Personal bias and staff turnover impact the accuracy of depending on estimators' views. The reported productivity figures do not reflect a contractor's performance, but rather the industry's average productivity rates [13]. Past project data generally yields the most accurate and trustworthy estimate [1]. As a result, proper modelling of construction labour productivity allows avoiding the subjectivity and irrelevance of the old technique. These models capture the variance in productivity with regard to the influencing input parameters, resulting in successful construction project planning and scheduling [14-15].

\section{Related Work}

Artificial intelligence is deemed to be an effective technique for forecasting construction labor productivity. Heravi and Eslamdoost [16] employed a back propagation neural network (BPNN) model to predict labour productivity. When early stopping and Bayesian regularization were compared, Bayesian regularization outperformed early stopping. A sensitivity analysis was also performed to assess the impact of each input element on the prediction performance of the models. El-Gohary et al. [1] applied neural networks to estimate construction labour productivity. To benchmark construction labour productivity, many activation and transfer functions, as well as a wide variety of influencing factors, were used. When compared to standard approaches in the literature, the suggested model produced more accurate findings.

Golnaraghi et al. [8] compared the results of BPNN, general regression neural network (GRNN), radial base function neural network (RBFNN), and adaptive neuro-fuzzy inference system (ANFIS) to evaluate labour productivity. According to the results, BPNN outperformed other approaches for predicting labor productivity. Mlybari [17] estimated labour productivity using GRNN, artificial neural networks (ANN), support vector machine (SVM), and multiple additive regression trees (MART). According to the findings, the GRNN model outperformed the other approaches for forecasting labour productivity in concrete pouring and finishing as well as steel fixing.

Mohammed Abdelkader et al. [18] compared an ensemble of machine learning models for the sake of estimating loss of productivity as a result of change orders. In the developed model, the loss of productivity was quantified with regards to type of work, its impact, number of change orders, their frequency, average size of change orders and change order hours. The utilized machine learning models encompassed radial basis neural network, generalized regression neural network, cascade forward neural network, Elman neural network, back propagation neural network, multiple linear regression and hybrid particle swarm optimization-liner regression. It was evinced that radial basis neural network surpassed other machine learning models attaining mean absolute percentage error, mean absolute error and root mean square error of $2.44 \%$, 0.014 and 0.027 , respectively.

Agrawal and Halder [19] studied factors that influence construction labour productivity. By adopting relative importance index, the levels of importance of the studied factors were explored. Results demonstrated that appointing competent project labour, payments on time and skilled labour were appended as the most implicating indicators on labour's productivity. Alrefaie et al. [20] deployed polynomial regression to forecast labour productivity of reinforcement rebar. In their model, a set of explanatory variables was studied such as rainfall distribution, solar radiation, dry bulb temperature, wind speed and relative humidity. Results illustrated that weather conditions managed to influence labour's productivity by $43 \%$.

Hai and Van Tam [21] built a regression-based model to analyse labour's productivity of construction workers. They tackled factors pertaining to work time, motivation, working safety, working conditions, natural environment, etc. It was anticipated that factors in relation with construction workers are highly influential on labour productivity. Dixit [22] investigated the factors influencing on-site construction 
productivity drawing on multiple regression and statistical analysis. It was revealed that change in scope, revision in drawings and response to change orders highly impact construction productivity.

\section{Model Development}

The framework of the developed model for forecasting the labour productivity of formwork assembly is presented in this section. The framework, as illustrated in Figure 1. The first step is to define the factors affecting labour productivity in high rise buildings. The present research study explores the implementation of eight types of data-driven machine learning models, namely ANFIS-GA, ANFIS-PSO, GRNN [23-24], BP-ANN [25-26], ENN [27-28], RT [29-30], SVM [31-32] and GPR [33-34]. The validation process is carried out hinging upon the performance metrics of MAPE, MAE, RMSE, RAE and RRSE. In the ANFIS-GA and ANFIS-PSO, genetic algorithm and particle swarm optimization algorithms are used to estimate the parameters of the membership function in the ANFIS model. Using the input and target data, the fuzzy inference system is built. The ANFIS model output is calculated, and error objective functions are minimized [35]. Some machine learning models may over perform with regards to some performance metrics. However, they may under perform with respect to others. Hence, average ranking algorithm is exploited to establish a consolidated ranking of the data-driven models [36-37]. Eventually, a correlation matrix is constructed to look into the dependencies between the input and output variables.

\section{Performance Metrics}

As discussed previously, the developed model accommodates the five performance evaluation metrics of MAPE, MAE, RMSE, RAE and RRSE that are described in Eq. 1, Eq. 2, Eq. 3, Eq. 4 and Eq. 5, respectively [3841].

$$
\begin{aligned}
& \text { MAPE }=\frac{100}{\mathrm{k}} \times \sum_{\mathrm{i}=1}^{\mathrm{K}} \frac{\left|\mathrm{P}_{\mathrm{i}}-\mathrm{O}_{\mathrm{i}}\right|}{\mathrm{O}_{\mathrm{i}}} \\
& \text { MAE }=\frac{1}{\mathrm{~K}} \sum_{\mathrm{i}=1}^{\mathrm{K}}\left|\left(\mathrm{O}_{\mathrm{i}}-\mathrm{P}_{\mathrm{i}}\right)\right| \\
& \text { RMSE }=\sqrt{\frac{1}{\mathrm{~K}} \sum_{\mathrm{i}=1}^{\mathrm{K}}\left(\mathrm{O}_{\mathrm{i}}-\mathrm{P}_{\mathrm{i}}\right)^{2}}
\end{aligned}
$$

$\mathrm{RAE}=\frac{\sum_{\mathrm{i}=1}^{\mathrm{K}}\left|\left(\mathrm{O}_{\mathrm{i}}-\mathrm{P}_{\mathrm{i}}\right)\right|}{\sum_{\mathrm{i}=1}^{\mathrm{K}}\left|\left(\mathrm{O}_{\mathrm{i}}-\mathrm{O}_{\mathrm{i}}{ }^{-}\right)\right|}$

$\operatorname{RRSE}=\sqrt{\frac{\sum_{\mathrm{i}=1}^{\mathrm{K}}\left(\mathrm{O}_{\mathrm{i}}-\mathrm{P}_{\mathrm{i}}\right)^{2}}{\sum_{\mathrm{i}=1}^{\mathrm{K}}\left(\mathrm{O}_{\mathrm{i}}-\mathrm{O}_{\mathrm{i}}^{-}\right)^{2}}}$

Where $\mathrm{K}$ is number of available observations in the dataset. $\mathrm{O}_{\mathrm{i}}$ and $\mathrm{P}_{\mathrm{i}}$ are the actual and predicted labour productivities, respectively. It should be highlighted that lower values of MAPE, MAE, RMSE, RAE and RRSE indicate more accurate intelligent data-driven model.

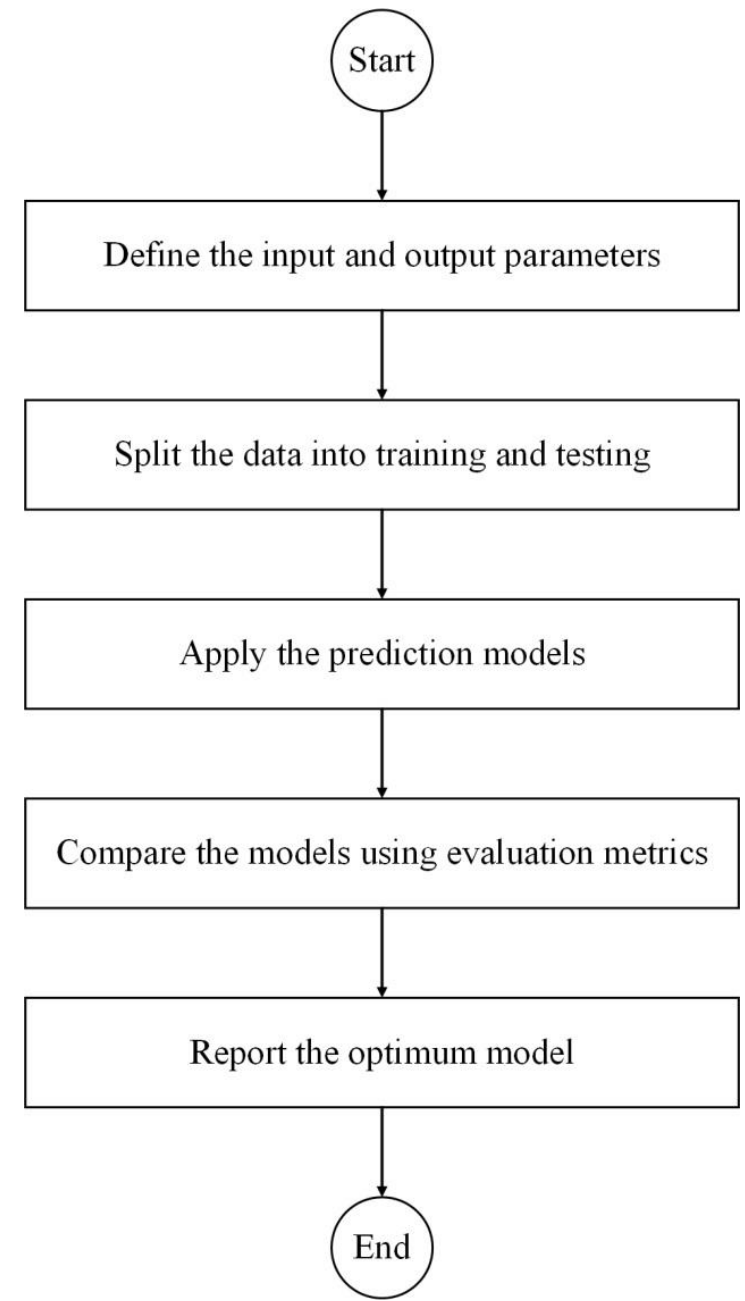

Figure 1. Flowchart for predicting formwork labour productivity.

\section{Numerical Example}

Over eighteen months, data on labour productivity was collected from two high-rise buildings in Montreal, Canada [42]. The first structure was built of concrete and had a flat slab construction system. It had 17 floors and a surface area of 68,000 $\mathrm{m} 2$, and it took three years to build. The second structure employed the 
same structural system as the first. These projects include a total of 221 data points for formwork activity. The data includes project, crew, and weather-related parameters. Data related to job type and procedure, as well as floor level, are classed as project data, whereas gang size and labor percentage belong to crew data. The factors utilized in the weather category include temperature, humidity, precipitation, and wind speed.

The aforementioned factors must be taken into account since they affect daily work productivity. Table 1 depicts additional statistical parameters for the nine variables. It should be noted that the work type includes three forms of formwork: slabs (1), walls (2), and columns (3). Furthermore, the work approach incorporates built-in place (1) and flying forms (2). The number of floors is referred to as the floor level. The gang size in the crew category refers to the number of people in a crew. In addition, the labour percentage is the ratio of labour size to gang size. Temperature, humidity, and wind speed are measured in Celsius ( $\left.\mathrm{C}^{\circ}\right)$, percentage (\%), and kilometres per hour, respectively. Furthermore, precipitation can be classified as no precipitation (0), light rain (1), snow (2), or rain (3).

The effectiveness of the developed data-driven models for forecasting formwork labour productivity is investigated in this study. To anticipate worker productivity in two high-rise buildings in Montreal, Canada, the traditional BP-ANN model is used as the benchmark model. The dataset is divided into two parts: 80 percent for training and 20 percent for testing.

Table 1. Statistical parameters of input and output factors.

\begin{tabular}{|c|c|c|c|c|}
\hline Variable & Min & Max & Mean & $\begin{array}{c}\text { Standard } \\
\text { deviation }\end{array}$ \\
\hline Work type (C1) & 1 & 3 & 1.43 & 0.51 \\
\hline $\begin{array}{c}\text { Work method } \\
\text { (C2) }\end{array}$ & 1 & 2 & 1.44 & 0.50 \\
\hline Floor level (C3) & 1 & 17 & 11.38 & 3.75 \\
\hline Gang size (C4) & 8 & 24 & 16.03 & 5.07 \\
\hline $\begin{array}{c}\text { Labour } \\
\text { percentage (C5) }\end{array}$ & 29 & 47 & 35.49 & 3.79 \\
\hline Temperature(C6) & -26 & 25 & 4.08 & 12.03 \\
\hline Humidity(C7) & 18 & 97 & 66.34 & 15.67 \\
\hline Precipitation (C8) & 0 & 3 & 0.28 & 0.60 \\
\hline Wind speed (C9) & 3 & 43 & 15.42 & 8.46 \\
\hline Productivity (Y1) & 0.82 & 2.53 & 1.57 & 0.35 \\
\hline
\end{tabular}

A sample of 50 data observations of the actual and predicted labour productivity using RT, BP-ANN and ANFIS-PSO are presented in Figures 2, 3 and 4, respectively. It can be noticed that RT managed to simulate the actual labour productivity accurately producing very close predicted values to the actual ones. As for BP-ANN, it managed to yield acceptable level of accuracies. However, it still underperformed in some data observations. With regards to ANFIS-PSO, it failed to predict the actual labour productivity resulting very far predicted values from the actual values.

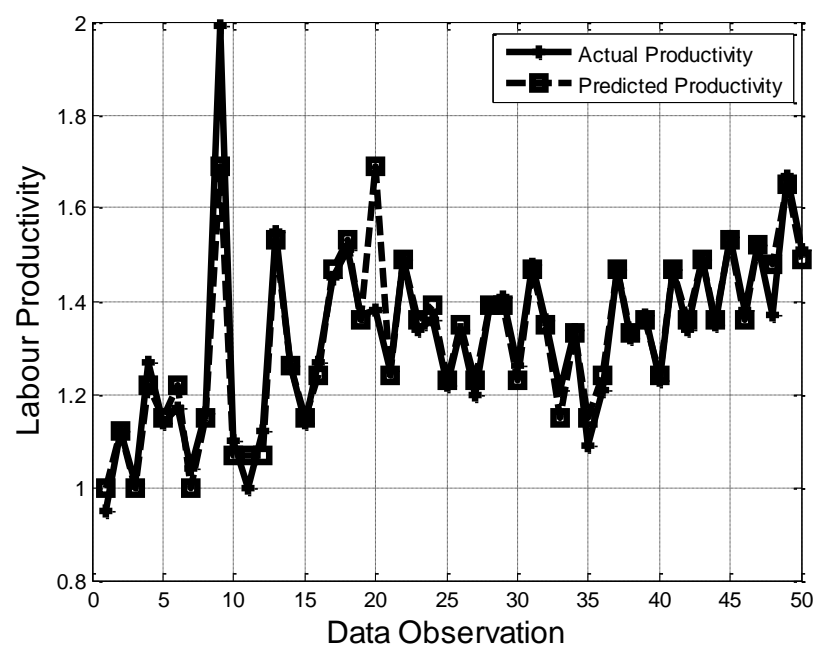

Figure 2: Actual and predicted labour productivities using RT

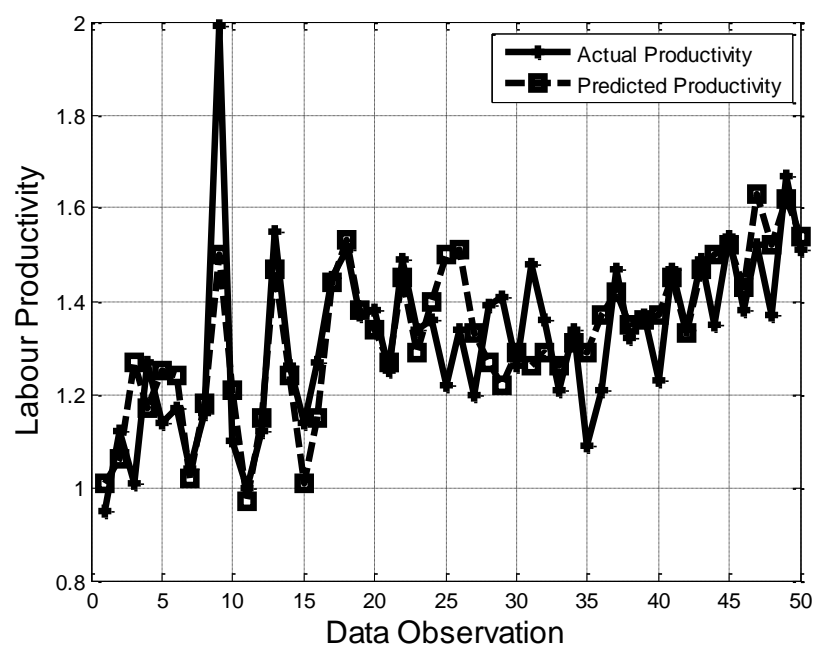

Figure 3: Actual and predicted labour productivities using BP-ANN

The error histograms with 25 bins in RT, BP-ANN and ANFIS-PSO models are depicted in Figures 5, 6 and 7 , respectively. It can observed that RT managed to induce very close values to zero error in most of the instances. 


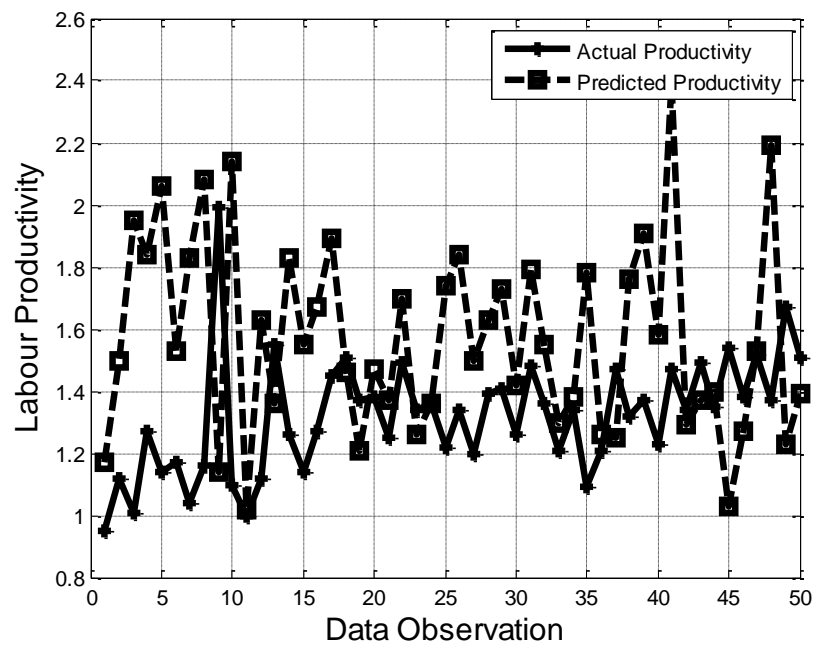

Figure 3: Actual and predicted labour productivities using ANFIS-PSO

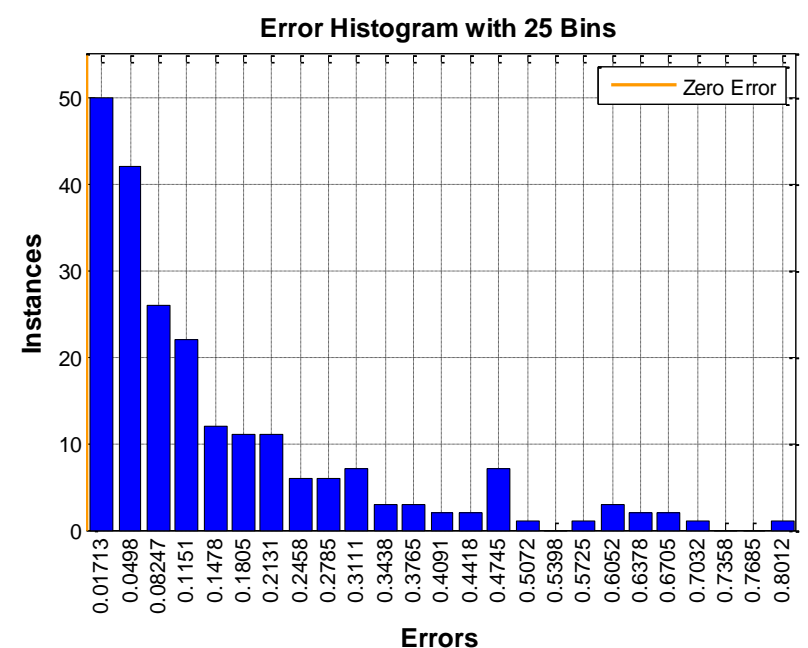

Figure 4: Error histogram in RT model Error Histogram with 25 Bins

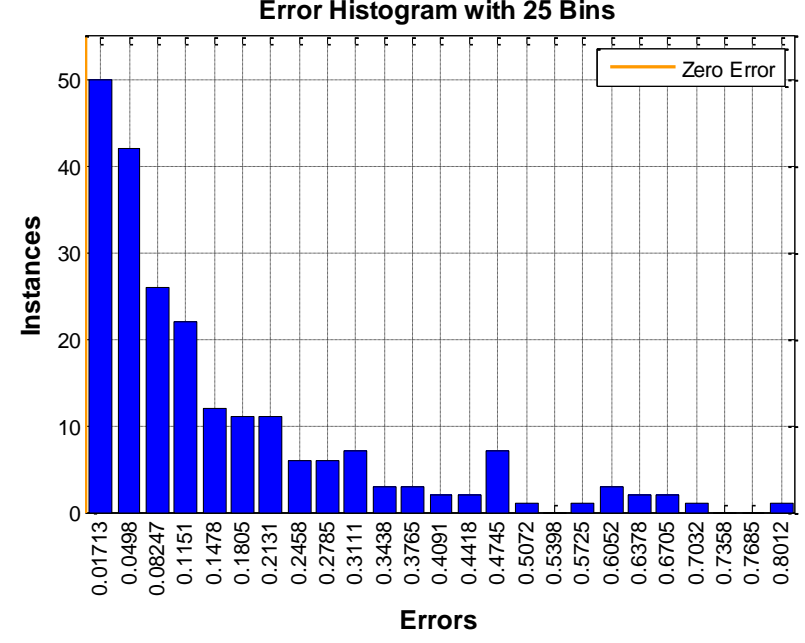

Figure 5: Error histogram in BP-ANN model

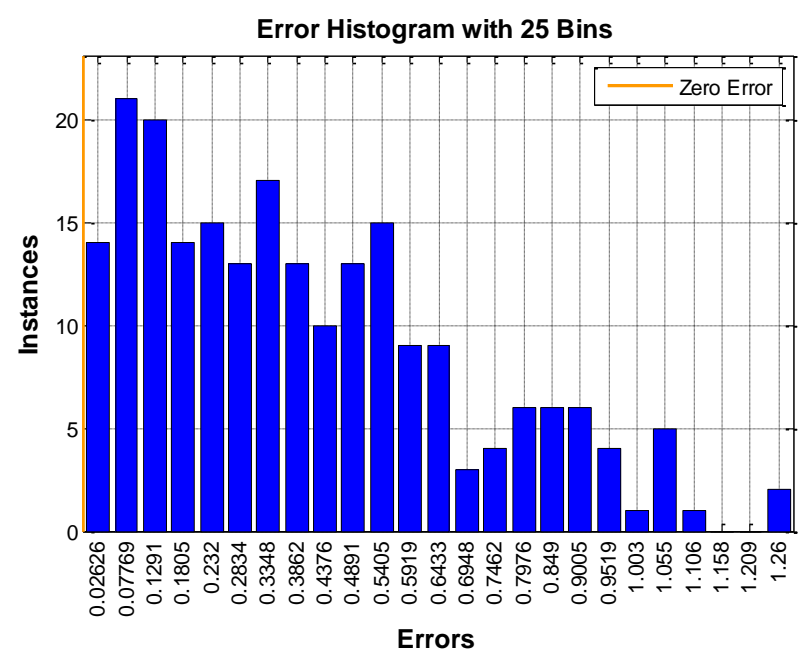

Figure 6: Error histogram in ANFIS-PSO model

Table 2 reports a comparison between simulated and actual labour productivity estimates. GRNN model accomplished high prediction performance, whereas it provided MAPE, MAE, RMSE, RAE and RRSE of 7.21\%, $0.1,0.22,0.35$ and 0.63 , respectively. GRNN also achieved very promising results attaining MAPE, MAE, RMSE, RAE and RRSE of 8.98\%, 0.13, 0.19, 0.45 and 0.54 , respectively. On the contrary, ANFIS-PSO yielded the highest prediction errors such that its values of MAPE, MAE, RMSE, RAE and RRSE are 26.26\%, 0.4, 0.5, 1.4 and 1.4, respectively. ENN obtained acceptable prediction performance with MAPE, MAE, RMSE, RAE and RRSE are 10.33\%, 0.15, 0.22, 0.52 and 0.62, respectively.

Table 2: Comparative analysis of the data-driven models for predicting labour productivity.

\begin{tabular}{|c|c|c|c|c|c|}
\hline $\begin{array}{c}\text { Prediction } \\
\text { model }\end{array}$ & MAPE & MAE & RMSE & RAE & RRSE \\
\hline ANFIS-GA & $23.47 \%$ & 0.35 & 0.44 & 1.22 & 1.25 \\
\hline ANFIS-PSO & $26.26 \%$ & 0.40 & 0.50 & 1.40 & 1.40 \\
\hline GRNN & $8.98 \%$ & 0.13 & 0.19 & 0.45 & 0.54 \\
\hline BP-ANN & $10.38 \%$ & 0.15 & 0.22 & 0.53 & 0.63 \\
\hline ENN & $10.33 \%$ & 0.15 & 0.22 & 0.52 & 0.62 \\
\hline RT & $7.21 \%$ & 0.10 & 0.22 & 0.35 & 0.63 \\
\hline SVM & $20.31 \%$ & 0.31 & 0.39 & 1.07 & 1.10 \\
\hline GPR & $10.03 \%$ & 0.149 & 0.21 & 0.52 & 0.59 \\
\hline
\end{tabular}


The results of the average ranking algorithm are recorded in Table 3. As can be seen, GRNN outranked the remainder of the data-driven models whereas it accomplished mean and standard deviation of 0.8 and 1.4, respectively. RT was ranked in the second place followed by GPR in the third place. On the other hand, ANFIS-PSO and ANFIS-PSO were ranked in the seventh and eight places, respectively. Analytical comparisons also illustrated that GRNN provided the most stable and robust performance with least standard deviation. However, RT and GPR experienced explicit variations across the multiple performance indicators.

Table 3: Final rankings of data-driven models.

\begin{tabular}{|c|c|c|c|}
\hline $\begin{array}{c}\text { Prediction } \\
\text { model }\end{array}$ & $\begin{array}{c}\text { Mean } \\
\text { ranking }\end{array}$ & $\begin{array}{c}\text { Standard } \\
\text { deviation } \\
\text { of rankings }\end{array}$ & $\begin{array}{c}\text { Final } \\
\text { ranking }\end{array}$ \\
\hline ANFIS-GA & 7 & 0 & 7 \\
\hline ANFIS-PSO & 8 & 0 & 8 \\
\hline GRNN & 1.8 & 0.40 & 1 \\
\hline BP-ANN & 4.6 & 0.49 & 5 \\
\hline ENN & 3.2 & 0.40 & 4 \\
\hline RT & 2.6 & 1.96 & 2 \\
\hline SVM & 6 & 0 & 6 \\
\hline GPR & 2.8 & 1.17 & 3 \\
\hline
\end{tabular}

Table 5 reports the correlation between the design input explanatory variables and labour productivity. It can be interpreted that the highest level of correlation existed between gang size and temperature, gang size and wind speed, and labour productivity and temperature. It is also shown that temperature and work method exhibit the highest influence on labour productivity. On the other hand, humidity and labour percentage have the least correlation with labour productivity. In this regard, the correlation values of work method, temperature, humidity and labour percentage with labour productivity are $-0.353,0.589,-0.053$ and 0.09 , respectively.

\section{Conclusion}

This study presented eight intelligent data-driven models for forecasting labour productivity in high rise buildings. To assess the effectiveness of the suggested models, historical data from two high-rise structures were collected. Eighty percent of the data was utilized to train the models, while the remaining twenty percent was used to test and validate the models. As input parameters for the models, nine factors related to the project, crew, and weather conditions were chosen. Performance analysis evinced that GRNN provided the lowest prediction error (MAPE 8.98\%, MAE 0.13, RMSE 0.19 , RAE 0.45 and RRSE 0.54). Nevertheless, ANFISPSO obtained the lowest prediction accuracies (MAPE 26.26\%, MAE 0.4, RMSE 0.5, RAE 1.4 and RRSE 1.4). In this regard, GRNN performed better than BP-ANN, ENN, SVM, GPR, ANFIS-GA and ANFIS-PSO by $13.97 \%$, $13.28 \%, \quad 54.8 \%, \quad 10.94 \%, \quad 60.27 \%$ and $60.98 \%$, respectively. It was also inferred that GRNN produced the most stable ranking over the five investigated performance indicators. As for GPR and RT, their rankings were highly variable with the performance indicators. It was also found that RT accomplished the second ranking based on the average ranking algorithm while ANFIS-GA and ANFIS-PSO were the lowest ranked intelligent data-driven models. The correlation analysis manifested that work method and temperature are highly correlated with formwork labour productivity while humidity and labour productivity are less influential on the labour productivity. As a result, the GRNN can be stand as an improved decision-making platform for predicting formwork labor productivity in high rise buildings. 
Table 4: Final rankings of data-driven models.

\begin{tabular}{|c|c|c|c|c|c|c|c|c|c|c|}
\hline & C1 & C2 & C3 & C4 & C5 & C6 & C7 & C8 & C9 & Y1 \\
\hline C1 & 1 & -0.761 & -0.052 & -0.175 & -0.135 & -0.122 & -0.110 & -0.037 & 0.065 & -0.353 \\
\hline C2 & & 1 & 0.225 & -0.036 & 0.177 & 0.078 & 0.176 & -0.057 & 0.030 & 0.328 \\
\hline C3 & & & 1 & -0.352 & 0.142 & 0.358 & 0.048 & -0.288 & 0.235 & 0.301 \\
\hline C4 & & & & 1 & -0.310 & 0.390 & -0.167 & 0.065 & -0.415 & 0.183 \\
\hline C5 & & & & & 1 & -0.120 & 0.219 & -0.063 & 0.051 & -0.053 \\
\hline C6 & & & & & & & 0.151 & -0.093 & -0.122 & 0.589 \\
\hline C7 & & & & & & & 1 & 0.338 & 0.026 & 0.090 \\
\hline C8 & & & & & & & & & 0.076 & -0.175 \\
\hline C9 & & & & & & & & & & -0.202 \\
\hline Y1 & & & & & & & & & & 1 \\
\hline
\end{tabular}

\section{References}

[1] El-Gohary KM, Aziz RF, Abdel-Khalek HA (2017) Engineering approach using ANN to improve and predict construction labor productivity under different influences. Journal of Construction Engineering and Management 143(8):1-10.

[2] Dixit S, Mandal SN, Thanikal JV, Saurabh K (2019) Evolution of studies in construction productivity: A systematic literature review (2006-2017). Ain Shams Engineering Journal 10(3):555-564.

[3] Dixit S, Mandal SN, Sawhney A, Singh S (2017) Relationship between skill development and productivity in construction sector: a literature review. International Journal of Civil Engineering and Technology 8(8):649-665.

[4] Duncan JR (2002) Innovation in the building sector: Trends and new technologies. In: technical conference of the institution of professional engineers of New Zealand, Building Research Association of New Zealand, Wellington, New Zealand.

[5] Gomar JE, Haas CT, Morton DP (2002) Assignment and allocation optimization of partially multiskilled workforce. Journal of Construction Engineering and Management 128(2):103-109.

[6] Hanna AS, Peterson P, Lee M (2002) Benchmarking productivity indicators for electrical/mechanical projects. Journal of Construction Engineering and Management 128(4):331-337.
[7] Allen SG. (1985) Why construction industry productivity is declining. The Review of Economics and Statistics 67(4):661-669.

[8] Golnaraghi S, Zangenehmadar Z, Moselhi O, Alkass S (2019) Application of artificial neural network(s) in predicting formwork labor productivity. Advances in Civil Engineering 2019:1-11.

[9] Hanna AS (2003) Effectiveness of innovative crew scheduling. Construction Industry Institute, Austin, United States.

[10] El-Batreek AH, Ezeldin AS, Elbarkouky MMG (2013) A framework for construction labor productivity improvement in Egypt. In: 2013 architectural engineering conference, ASCE, Reston, United States.

[11] Durdyev S, Ismail S, Kandymov N (2018) Structural equation model of the factors affecting construction labor productivity. Journal of Construction Engineering and Management 144(4):1-11.

[12] Abdel-Wahab M, Vogl B (2011) Trends of productivity growth in the construction industry across Europe, US and Japan. Construction management and economics 29(6):635-644.

[13] Thomas HR (2010) Quantification of losses of labor efficiencies: Innovations in and improvements to the measured mile. Journal of Legal Affairs and Dispute Resolution in Engineering and Construction 2(2):106112. 
[14] Song L, AbouRizk SM (2008) Measuring and modeling labor productivity using historical data. Journal of Construction Engineering and Management 134(10):786-794.

[15] Elshaboury, N., Al-Sakkaf, A., Alfalah, G. Mohammed Abdelkader, E (2021) Improved Adaptive Neuro-Fuzzy Inference System Based on Particle Swarm Optimization Algorithm for Predicting Labor Productivity. 2nd International Conference on Civil Engineering Fundamentals and Applications (ICCEFA'21) 1-9.

[16] Heravi G, Eslamdoost E (2015) Applying artificial neural networks for measuring and predicting construction labor productivity. Journal of Construction Engineering and Management 141(10):111.

[17] Mlybari EA (2020) Application of soft computing techniques to predict construction labor productivity in Saudi Arabia. International Journal of GEOMATE 19(71):203-210.

[18] Mohammed Abdelkader, E., El-kabalawy, M., Assad, A., Al-Sakkaf, A., Elshaboury, N. (2020). An Extensive Machine Learning-based Comparative Analysis for Mimicking Loss of Productivity as a Result of Change Orders. The Journal of Scientific and Engineering Research, 7(12): 81-93.

[19] Agrawal, A., Halder, S (2020) Identifying factors affecting construction labour productivity in India and measures to improve productivity. Asian Journal of Civil Engineering 21(4):569-579.

[20] Alrefaie, A. M., Abdul-Samad, Z., Salleh, H., Alashwal, A. M., Amos, D (2021) Modelling labour productivity of reinforcement bar using polynomial regression: a study on a tropical country's weather. International Journal of Construction Management 110.

[21] Hai, D. T., Van Tam, N (2020) Application of the Regression Model for Evaluating Factors Affecting Construction Workers' Labor Productivity in Vietnam. The Open Construction and Building Technology Journal 13(1):353-362.

[22] Dixit, S (2018) Analysing Enabling Factors Affecting the On-site Productivity in Indian Construction Industry. Periodica Polytechnica Architecture 49(2):185-193.

[23] Alam, M. S., \& Gazder, U (2020) Shear strength prediction of FRP reinforced concrete members using generalized regression neural network. Neural Computing and Applications 32(10):6151-6158.
[24] Mohammed Abdelkader, E., Al-Sakkaf, A., Ahmed, $\mathrm{R}$ (2020) A comprehensive comparative analysis of machine learning models for predicting heating and cooling loads. Decision Science Letters 9(3):409-420.

[25] Barham, W. S., Rabab'ah, S. R., Aldeeky, H. H., Al Hattamleh, O. H (2020) Mechanical and Physical Based Artificial Neural Network Models for the Prediction of the Unconfined Compressive Strength of Rock. Geotechnical and Geological Engineering, 38(5):4779-4792.

[26] Sinshaw, T. A., Surbeck, C. Q., Yasarer, H., Najjar, Y (2019) Artificial Neural Network for Prediction of Total Nitrogen and Phosphorus in US Lakes. Journal of Environmental Engineering 145(6):1-11.

[27] Kashani, M., Gheys, R (2016) Comparison of Three Intelligent Techniques for Runoff Simulation. Civil Engineering 4(5):1-9.

[28] Mohammed Abdelkader, E., Moselhi, O., Marzouk, M. and Zayed, T (2021) An Integrative Evolutionarybased Method for Modeling and Optimizing Resource Allocation of Bridge Deck Replacement Projects, Journal of Construction Engineering and Management 147(9):1-23.

[29] Liang, M., Mohamad, E. T., Faradonbeh, R. S., Jahed Armaghani, D., Ghoraba, S (2016) Rock strength assessment based on regression tree technique. Engineering with Computers 32(2):343-354.

[30] Effati, M., Rajabi, M. A., Hakimpour, F., Shabani, S (2015) Prediction of Crash Severity on Two-Lane, Two-Way Roads Based on Fuzzy Classification and Regression Tree Using Geospatial Analysis. Journal of Computing in Civil Engineering 29(6):1-14.

[31] Sonmez, R., \& Sözgen, B (2017) A support vector machine method for bid/no bid decision making. Journal of Civil Engineering and Management 23(5): 641-649.

[32] Sahoo, B. B., Jha, R., Singh, A., Kumar, D (2019) Application of Support Vector Regression for Modeling Low Flow Time Series. KSCE Journal of Civil Engineering 23(2):923-934.

[33] Chen, B., Shen, L., Zhang, H (2021) Gaussian Process Regression-Based Material Model for Stochastic Structural Analysis. ASCE-ASME Journal of Risk and Uncertainty in Engineering Systems, Part A: Civil Engineering 7(3):1-12.

[34] Momeni, E., Dowlatshahi, M. B., Omidinasab, F., Maizir, H., Armaghani, D. J (2020) Gaussian Process Regression Technique to Estimate the Pile Bearing Capacity. Arabian Journal for Science and Engineering 45(10):8255-8267. 
[35] Termeh SV, Khosravi K, Sartaj M, Keesstra SD, Tsai FT, Dijksma R, Pham BT (2019) Optimization of an adaptive neuro-fuzzy inference system for groundwater potential mapping. Hydrogeology Journal 27(7):2511-2534.

[36] Mohammed Abdelkader, E., Moselhi, O., Marzouk, M. Zayed, T (2020) Hybrid Elman Neural Network and Invasive Weed Optimization Method for Bridge Defects Recognition, Transportation Research Record: Journal of the Transportation Research Board 2675(3):167-199.

[37] Yu, D., Hong, J., Zhang, J., Niu, Q (2018) MultiObjective Individualized-Instruction TeachingLearning-Based Optimization Algorithm. Applied Soft Computing, 62:288-314.

[38] Bui, D. T., Moayedi, H., Gör, M., Jaafari, A.,Foong, L. K (2019) Predicting slope stability failure through machine learning paradigms. ISPRS International Journal of Geo-Information 8(9):1-35.

[39] Di Nunno, F., Granata, F (2020) Groundwater level prediction in Apulia region (Southern Italy) using NARX neural network. Environmental Research 190:1-17.

[40] Kashkaki, Z., Banejad, H., Heydari, M (2018) Application of ANN in Estimating Discharge Coefficient of Circular Piano Key Spillways. Journal of Soft Computing in Civil Engineering 2(3): 39-49.

[41] Lu, H., Xu, Z.-D., Iseley, T., Matthews, J. C (2021) Novel Data-Driven Framework for Predicting Residual Strength of Corroded Pipelines. Journal of Pipeline Systems Engineering and Practice 12(4):1-10.

[42] Khan ZU (2005) Modeling and parameter ranking of construction labor productivity. Dissertation, Concordia University. 